\title{
Glutaric Acidemia Type II: Heterogeneity of Clinical and Biochemical Phenotypes ${ }^{1}$
}

\author{
JAMES P. LOEHR, STEPHEN I. GOODMAN, AND FRANK E. FRERMAN \\ Department of Pediatrics, University of Colorado School of Medicine, Denver, Colorado 80262
}

\begin{abstract}
We have examined 23 fibroblast lines from patients with neonatal and late onset glutaric acidemia type II and fibroblasts from four parents of these patients. Fifteen of these patients are previously unreported. Results of these investigations show deficiency of electron transfer flavoprotein or electron transfer flavoprotein-ubiquinone oxidoreductase activity in all of the patients' fibroblasts. Immunoblots indicate that the steady state levels of the antigens is very low or undetectable in most of the neonatal onset patients; however, cross-reacting antigen without electron transfer activity is observed in several glutaric acidemia type II fibroblast lines. Assay of parental lines confirm the autosomal transmission of deficiencies of proteins. Of particular interest is the clinical heterogeneity among these patients. Patients may present with an extrapyramidal movement disorder as observed in glutaric aciduria type I, without the typical organic aciduria typical of glutaric acidemia type II even in the presence of severe enzyme deficiency, or with renal cystic dysplasia accompanying electron transfer flavoprotein deficiency. Renal cystic dysplasia had previously been reported only in patients with electron transfer flavoprotein-ubiquinone oxidoreductase deficiency. (Pediatr Res 27: 311-315, 1990)
\end{abstract}

\section{Abbreviations}

GA2, glutaric acidemia type II

ETF, electron transfer flavoprotein

ETF-QO, electron transfer flavoprotein-ubiquinone oxidoreductase

MCAD, medium chain (general) acyl-CoA dehydrogenase $Q_{1}$, 2,3-dimethoxy-5-methyl-6-isopentenyl-1,4-benzoquinone

GA2 is an inborn error of fatty and amino acid metabolism characterized by hypoketotic hypoglycemia, metabolic acidosis, and the urinary excretion of substrates, or the metabolites of substrates, of mitochondrial flavoprotein dehydrogenases that transfer electrons to ubiquinone via ETF and ETF-QO. In some patients, the disease is due to deficiency of ETF, a soluble flavin adenine dinucleotide-containing heterodimer located in the mitochondrial matrix (1-5), and in others the disease is due to a deficiency of ETF-QO, an iron-sulfur flavoprotein located in the inner mitochondrial membrane $(3,6-8)$.

Received September 12, 1989; accepted November 2, 1989.

Correspondence Dr. Frank E. Frerman, Department of Pediatrics, Box C-233, University of Colorado School of Medicine, 4200 East Ninth Avenue, Denver, CO 80262 .

Supported by NIH Grants DK38687, HD08315, and HD04024.

${ }^{1}$ Portions of this work were presented at the International Symposium on Biochemical, Clinical and Molecular Aspects of Fatty Acid Oxidation, Philadelphia, PA, November 1988.
Patients who develop symptoms during the first few days of life usually do not survive for more than a few weeks, and many of them show anomalies such as renal cystic dysplasia, facial dismorphism, locker bottom feet, and abnormalities of the external genitalia (9). Patients with milder forms of the disease may develop episodes of hypoketotic hypoglycemia, acidosis, and hepatomegaly in infancy or childhood, or may present even later with muscle weakness and carnitine deficiency (10-12). The purpose of this report is to describe a new catalytic assay for $\mathrm{ETF}$, and the clinical features and catalytic and immunologic properties of the two electron transferases in 23 patients with severe and mild forms of GA2. Fifteen of these patients have not been previously reported. The results show that (1) renal cystic dysplasia may occur in ETF deficiency, but less frequently than in ETF-QO deficiency, (2) as with glutaric acidemia type I, the disease may present with extrapyrimidal movement disorder due to degeneration of the basal ganglia, and (3) urine organic acids may be normal even in patients with severe enzymatic deficiency. One patient was found with an apparent primary defect in the smaller, or $\beta$-ETF subunit. As expected, we also found that mutations of ETF and ETF-QO can affect activity without altering protein size or reactivity with polyclonal antibodies. The data also provide additional evidence that ETF and ETF-QO deficiencies are inherited as autosomal recessive traits.

\section{MATERIALS AND METHODS}

Patient material. Cultured fibroblasts were grown in Eagle's minimal essential medium containing Earle's salts, $10 \%$ fetal bovine serum, antibiotics, and nonessential amino acids. Patients from whom fibroblast lines 1441 (13), $1196(14), 1728(15), 1902$ (16), $1730(17), 1808(18), 1691(3,8), 1591(10)$, and $1592(11)$ were derived have been described. Those patients from whom the other cell lines were obtained have not been reported, and brief descriptions of these patients follow.

Line 1692 was from the fetal sibling of a girl who had died at $3 \mathrm{~d}$ of age with hypoglycemia, acidosis, and an acrid odor, and whose autopsy showed fatty degeneration of heart, liver, and renal tubular epithelium, and dilatation of the renal collecting tubules. Large quantities of glutaric acid were detected in the liver. A diagnosis of GA2 was suggested by increased $(2.6 \mu \mathrm{g} /$ $\mathrm{mL}$ ) glutaric acid in amniotic fluid and, upon termination of pregnancy, fetal autopsy showed large quantities of fat in the liver. The couple has since had another pregnancy in which glutaric acid was not increased in amniotic fluid, and which resulted in the birth of an unaffected child.

Line 1803 was from the aborted sibling of a girl who had died at $3 \mathrm{~d}$ of age with hypothermia and apnea, with postmortem findings of microvesicular lipid in heart, liver, and large amounts of glutaric acid in liver and kidney. Pregnancy was terminated when glutaric acid was found to be increased in amniotic fluid at $15 \mathrm{wk}$; the fetus showed no gross abnormalities. Glutaric acid 
was not increased in the amniotic fluid of a later pregnancy, which resulted in the birth of an unaffected infant.

Line 1846 was from a female infant who developed hypoglycemia, lethargy, tachypnea, and metabolic acidosis during the first hours of life, and died $4 \mathrm{~d}$ later. Glutaric acid, sarcosine, and other compounds typical of GA2 were detected in urine, which also contained pipecolic acid. Autopsy showed fatty changes in liver parenchyma, cardiac fibers, and cells of the proximal renal tubules. There was no renal cystic dysplasia. Lines 1847 and 1848 are from the mother and father of this child.

Line 1851 was from a boy who at 10 mo of age showed failure to thrive, hypotonia, and gross motor delays, with episodes of ketotic hypoglycemia associated with infections. Urine organic analysis showed increased glutaric, 5-hydroxyhexanoic, adipic, suberic, and sebacic acids, and on another occasion, only increased adipic, suberic, and sebacic acids. Urine octanoyl carnitine and phenylpropionylglycine were not elevated. The child is now $3 \mathrm{y}$ of age, and is doing well without treatment.

Line 1863 was from a male infant with no apparent congenital anomalies who was diagnosed as having GA2 at 2 mo of age on the basis of urine organic acid analysis. He died at home during the 1 st $y$ of life, and autopsy was not performed.

Line 1865 was from a 19-wk female abortus in whom the diagnosis of GA2 was made by detection of increased glutaric acid in amniotic fluid and whose kidneys were enlarged secondary to renal cystic dysplasia. The first child of these parents, a girl, had multiple craniofacial anomalies including low set ears, flat facies, and occipital prominence, and had died at $2 \mathrm{~d}$ of age with metabolic acidosis, "the smell of sweaty feet," and organic acids typical of GA2. Autopsy had shown large cystic kidneys filling the abdomen, and cardiomegaly with ventricular hypertrophy.

Line 1879 was from a male infant with mild facial dysmorphism who developed transient hypoglycemia, acidosis, hypotonia, and possible airway obstruction during the first $11 \mathrm{~d}$ of life. Ethylmalonic and adipic acids were slightly elevated in urine. $\mathrm{He}$ did not improve on riboflavin, carnitine, and a low-fat diet, and died at 3 mo of age. Autopsy showed only possible immune glomerulopathy without renal cystic dysplasia, and diffuse gliosis most marked in the brainstem.

Line 1890 was from a North American Indian male infant who presented with hypotonia, acidosis, and hypoglycemia, and died at $19 \mathrm{~d}$ of age. Urine organic acids were diagnostic of GA2, and autopsy showed diffuse fatty infiltration of the heart and skeletal muscles, microvascular fat in hepatic parenchymal cells, and small kidneys with a few cysts and dysplatic changes. Fibroblasts from this patient were previously reported to be in the same complementation group as others deficient in ETF-QO (19).

Line 1894 was from a female infant without obvious congenital anomalies, who was diagnosed as having GA2 on the basis of urine organic acid analysis. The child, who was apparently doing well on carnitine and a diet low in protein and fat, died at home, and autopsy was not performed.

Line 1903 was from a baby with an unexplained episode of metabolic acidosis during the newborn period, and who later developed feeding difficulty and became irritable. At 8 mo she had proximal muscle weakness and profound hypotonia, and then deteriorated further, intermittently assuming dystonic postures. Organic acid analysis showed small amounts of compounds typical of GA2. She died at 4 y of age and after autopsy showed dilatation of the lateral ventricals and symmetrical shrinkage of the caudate and putamen with normal globis pallidus. The activity of glutaryl-CoA dehydrogenase in fibroblasts was assayed and found to be normal. Lines 1904 and 1905 were from the mother and father of the child, who were first cousins.

Line 1916 was from a female infant who presented during the 1 st $\mathrm{d}$ of life with hypoglycemia, hypothermia, metabolic acidosis and a "smell of sweaty feet"; she developed hyperammonemia shortly thereafter, and died on the 11 th d of life. Autopsy showed enlarged kidneys containing numerous fluid-filled cysts, and marked accumulation of lipid in hepatocytes and cardiac myocytes.

Line 1918 was from a female infant with a high forehead and several other dysmorphic features, who developed acidosis, hypoglycemia, and an acrid odor during the 1st $d$ of life, with urine showing the typical organic acid pattern of GA2. At $7 \mathrm{~d}$ of age, when the diagnosis was made, serum carnitine values were: total carnitine, $39.2 \mu \mathrm{M}$, free carnitine, $2.2 \mu \mathrm{M}$, and esterified carnitine, $37 \mu \mathrm{M}$ (normal mean values: total carnitine, $50 \mu \mathrm{M}$, free carnitine, $45 \mu \mathrm{M}$, and esterified carnitine, $5 \mu \mathrm{M}$ ). She was treated with oral carnitine and riboflavin. After $11 \mathrm{~d}$ of carnitine and riboflavin therapy, serum carnitine values were $57.8 \mu \mathrm{M}$ total, $26.2 \mu \mathrm{M}$ free, and $31.6 \mu \mathrm{M}$ esterified. An echocardiogram at 14 days of age showed a severe cardiomyopathy, but a repeat study was normal 2 mo later. She remained hypotonic and developmentally delayed, and died suddenly at 13 mo of age with acidosis and hypoglycemia. Autopsy showed marked fatty degeneration of the heart, and moderate infiltration of the liver.

Line 1935 was from a 19-y-old woman who had developed progressive weakness and intolerance to fasting, with shaking and sweats relieved by oral sweets during childhood. She was hospitalized when she was 18 y old with marked fatigue, muscle weakness, and hepatomegaly, which cleared spontaneously. Three mo before death, an episode of marked muscle weakness and hypoglycemia responded to glucose, and at this time she showed proximal upper and lower limb myopathy, hepatomegaly, and mild hyperammonemia, and a skeletal muscle biopsy demonstrated a lipid storage myopathy. Urine organic acids were typical of GA2 and were normalized with intravenous riboflavin and carnitine. She died from adult respiratory distress syndrome secondary to aspiration. Autopsy showed a fatty liver and heavy, consolidated lungs.

Line 1966 was from a girl whose 1st y of life was normal except for episodes of vomiting, lethargy, and pallor at 5 and 6 mo of age. The first episode responded dramatically to i.v. glucose, but the second progressed to respiratory arrest from which the patient recovered. Then 3 mo later, when she was well, urine organic acid analysis showed large amounts of adipic, moderate amounts of sebacic and suberic acids, and small amounts of glutaric acid. Of three urines obtained an additional 3 mo later, when she was again clinically well, one showed moderate dicarboxylic aciduria with dodecanedioic acid but without glutaric acid, one showed minimal dicarboxylic aciduria with dodecanedioic acid with glutaric acid, and another was entirely normal.

Enzyme preparations and assays. MCAD was prepared as described (20) and had a $\mathrm{A}_{270 \mathrm{~nm}} / \mathrm{A}_{448 \mathrm{~nm}}=5.3-5.6$; its concentration was determined using $\epsilon_{448 \mathrm{~nm}}=15.4 \mathrm{mM}^{-1}(21)$. ETF was purified essentially as described by Husain and Steenkamp (22) and had a $\mathrm{A}_{270 \mathrm{~nm}} / \mathrm{A}_{436 \mathrm{~nm}}=5.8-5.6$; its concentration was determined using $\epsilon_{436 \mathrm{~nm}}=13.4 \mathrm{mM}^{-1}$ (2). ETF-QO was purified essentially as described by Beckmann and Frerman (7) and its concentration was determined using $\epsilon_{430 \mathrm{~nm}}=24 \mathrm{mM}^{-1}$.

Fibroblasts from two $490 \mathrm{~cm}^{2}$ roller bottles were trypsinized, washed twice with $\mathrm{PBS}$, and the pellets were stored at $-70^{\circ} \mathrm{C}$; ETF and ETF-QO activities were stable in the frozen fibroblasts for at least $3 \mathrm{mo}$. Pellets were thawed and suspended in $0.5 \mathrm{~mL}$ of $10 \mathrm{mM} \mathrm{HEPES}\left(\mathrm{K}^{+}\right), \mathrm{pH} 7.8$, containing $10 \%$ ethylene glycol immediately before enzyme assay, disrupted by sonication, and centrifuged for $1 \mathrm{~h}$ at $100000 \times g$. Supernatant fractions were assayed for ETF activity and membrane fractions were detergent extracted and assayed for ETF-QO activity (3).

ETF was assayed at $25^{\circ} \mathrm{C}$ in $0.6 \mathrm{~mL}$ reaction mixtures containing $20 \mathrm{mM}$ Tris- $\mathrm{HCl}, \mathrm{pH} 7.5,130 \mu \mathrm{M}$ octanoyl-CoA, $70 \mu \mathrm{M} \mathrm{Q}$, $0.4 \mu \mathrm{M}$ MCAD (as flavin), and $0.25 \mu \mathrm{M}$ ETF-QO; reactions were initiated by the addition of $30-150 \mu \mathrm{g}$ of soluble fibroblast protein, and the reduction of $Q_{1}$ was assayed spectrophotometrically at $275 \mathrm{~nm}\left(\epsilon_{275 \mathrm{~nm}}=7.3 \mathrm{mM}^{-1}\right)(23)$. Saturating concentrations of MCAD, octanoyl-CoA, ETF-QO, and $\mathrm{Q}_{1}$ were deter- 
mined in preliminary experiments. Nonspecific decrease in absorbance at $275 \mathrm{~nm}$ was determined for each sample in reaction mixtures lacking ETF-QO. Figure 1 shows the dependence of the rate of $Q_{1}$ reduction upon added soluble fibroblast protein and the ETF-QO-independent rates that were subtracted from the ETF-QO-dependent rates. Variation of activity using the same extract was less than $10 \%$ and variation of activity between different extracts from the same fibroblast line assayed at different times was less than $15 \%$. ETF activity was stable for at least $2 \mathrm{~d}$ when the soluble supernatant fractions were stored frozen at $-70^{\circ} \mathrm{C}$. This assay is capable of detecting at least $0.5 \mathrm{nM}$ ETF when calibrated with purified porcine ETF and is six to eight times more sensitive than a previously described dye-coupled assay and does not require the isolation of a fibroblast mitochondrial fraction (5). ETF-QO was assayed by comproportionation of 2-electron reduced ETF and oxidized ETF $(3,7)$. Protein was determined by the method of Lowry et al. (24) as modified by Miller (25). In all cases, $1 \mathrm{mU}$ of enzyme activity is equal to 1 nmol of product formed per min at $25^{\circ} \mathrm{C}$.

Antibody preparations. The IgG fractions obtained by $\left(\mathrm{NH}_{4}\right)_{2} \mathrm{SO}_{4}$ fractionation of rabbit antisera against porcine ETF and ETF-QO (3) were affinity purified on 1-mL columns of ETFQO coupled to Affigel-15, or ETF coupled to Affigel-10. The

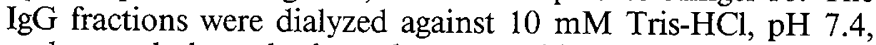
and passed through the column, equilibrated with the same buffer, three times. The column was washed until no protein eluted, and the specific antibodies were eluted with $0.1 \mathrm{M}$ glycine$\mathrm{HCl}, \mathrm{pH}$ 2.7. Antibody-containing fraction were immediately neutralized with $1 \mathrm{M}$ Trizma base, concentrated, dialyzed against $10 \mathrm{mM}$ Tris- $\mathrm{HCl}, \mathrm{pH} \mathrm{7.4}$, and stored at $4^{\circ} \mathrm{C}$ in the presence of $0.04 \%$ sodium azide at a concentration of $0.5-1.0 \mathrm{mg} / \mathrm{mL}$.

Electrophoresis and immunoblotting. Fibroblast pellets stored at $-70^{\circ} \mathrm{C}$ were suspended in $10 \mathrm{mM}$ Tris- $\mathrm{HCl}, \mathrm{pH} 7.4$, containing $1 \mathrm{mM}$ each of phenylmethyl sulfonyl fluoride, tosyl-L-lysine chloromethyl ketone, and tosylamide-2-phenylethyl chloromethyl ketone and sonicated and centrifuged as described above. Soluble and particulate proteins $(80 \mu \mathrm{g})$ were electrophoresed on $10-15 \%$ polyacrylamide gels in the presence of SDS (26) and transferred to nitrocellulose (27). ETF and ETF-QO were detected with the appropriate antibody and alkaline phosphataseconjugated goat anti-rabbit immunoglobulin or ${ }^{125} \mathrm{I}$-protein $\mathrm{A}$.

Materials. The water-soluble ubiquinone homolog, $\mathrm{Q}_{1}$, was the generous gift of Eisai Chemical Corp., Kyoto, Japan. ${ }^{125} I-$ labeled protein A was purchased from ICN Radiochemicals, Costa Mesa, CA. Alkaline phosphatase-conjugated goat antirabbit Ig was from Promega Biotec, Madison, WI. Affigel-10 and Affigel-15 were obtained from Bio-Rad Laboratories, Richmond,

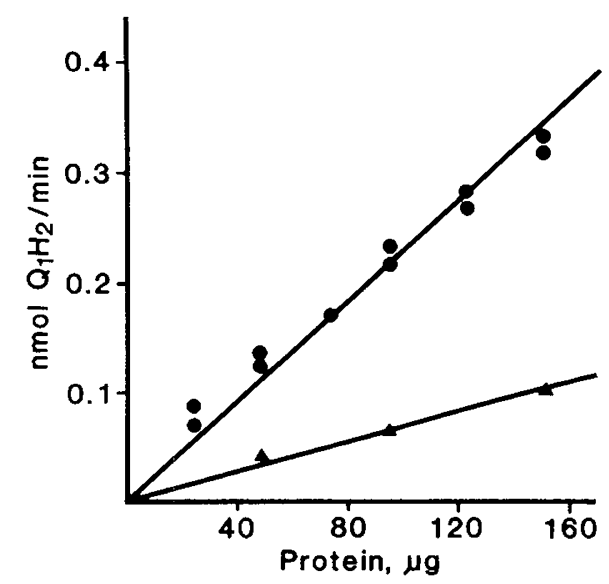

Fig. 1. Assay of ETF in a crude extract of human fibroblasts; dependence of $\mathrm{Q}_{1}$ reduction upon the concentration of added fibroblast protein. ETF activity was assayed as described in Materials and Methods. The ETF-QO dependent $(\bullet)$ and ETF-QO independent $(\boldsymbol{\Delta})$ reduction of $\mathrm{Q}_{1}$ are indicated.
CA. Octanoyl-CoA was from Sigma Chemical Co., St. Louis, MO. All other chemicals were the best grade commercially available.

\section{RESULTS}

ETF and ETF-QO in GA2 fibroblasts. Table 1 shows the electron transferase activities of ETF and ETF-QO in extracts of control and GA2 fibroblasts. Nine patients with neonatal onset GA2 were deficient in ETF activity and eight were deficient in ETF-QO activity. Of six patients with late onset GA2, three were deficient in ETF, and three were deficient in ETF-QO.

ETF-QO activity in fibroblasts from the parents of patient 1846 , and ETF activity from the parents of patient 1903, were intermediate between patient and control values. These observations confirm earlier indications that deficiencies of ETF and ETF-QO are inherited as autosomal recessive traits (3).

Figures 2 and 3 show the results of immunoblotting experiments that were used to determine whether there were major changes in the steady state levels or mol wt of ETF subunits or ETF-QO. Entire gels are shown in Figures $2 B$ and $3 A$ and $B$. Immunoblots of the two proteins in some of these lines, i.e. $1441,1196,1730$, and 1691, have been presented previously (3) and are presented here for sake of completeness with the development of the catalytic assay for ETF. Among the ETF-deficient

Table 1. ETF and ETF-QO activity in GA2 fibroblasts

\begin{tabular}{|c|c|c|}
\hline $\begin{array}{l}\text { Control range } \\
(\text { mean } \pm \mathrm{SD})\end{array}$ & $\begin{array}{c}\mathrm{ETF} \\
\mathrm{mU} / \mathrm{mg} \text { protein } \\
1.10-2.50 \\
1.70 \pm 0.40 \\
n=11\end{array}$ & $\begin{array}{c}\text { ETF-QO } \\
\mathrm{mU} / \mathrm{mg} \text { protein } \\
5.4-20.5 \\
14.1 \pm 3.9 \\
n=20\end{array}$ \\
\hline \multicolumn{3}{|l|}{ ETF deficiency } \\
\hline \multicolumn{3}{|l|}{ Neonatal onset } \\
\hline 1441 & 0.20 & 12.7 \\
\hline 1196 & 0.05 & 13.5 \\
\hline 1728 & 0.32 & 9.8 \\
\hline 1902 & $\leq 0.01$ & 13.0 \\
\hline 1803 & 0.11 & 5.5 \\
\hline 1863 & $\leq 0.01$ & 11.3 \\
\hline 1894 & 0.08 & 9.1 \\
\hline 1916 & 0.05 & 4.4 \\
\hline 1918 & 0.15 & 9.3 \\
\hline \multicolumn{3}{|l|}{ Late onset } \\
\hline 1851 & 0.48 & 15.3 \\
\hline 1903 & 0.10 & 18.6 \\
\hline 1966 & 0.03 & 10.7 \\
\hline \multicolumn{3}{|l|}{ ETF-QO deficiency } \\
\hline \multicolumn{3}{|l|}{ Neonatal Onset } \\
\hline 1730 & 3.8 & $\leq 0.1$ \\
\hline 1691 & 2.7 & $\leq 0.1$ \\
\hline 1692 & 1.8 & $\leq 0.1$ \\
\hline 1808 & 2.3 & 0.4 \\
\hline 1846 & 1.8 & $\leq 0.1$ \\
\hline 1865 & 2.6 & $\leq 0.1$ \\
\hline 1879 & 1.5 & $\leq 0.1$ \\
\hline 1890 & 1.3 & $\leq 0.1$ \\
\hline \multicolumn{3}{|l|}{ Late Onset } \\
\hline 1591 & 0.7 & 2.5 \\
\hline 1592 & 1.2 & 2.9 \\
\hline 1935 & 1.8 & 2.9 \\
\hline \multicolumn{3}{|l|}{ Parental lines } \\
\hline $1847 *$ & 1.10 & 4.3 \\
\hline $1848^{*}$ & Not done & 4.8 \\
\hline $1904 \dagger$ & 1.00 & Not done \\
\hline $1905 \dagger$ & 1.00 & Not done \\
\hline
\end{tabular}

* Parents of 1846 .

$\dagger$ Parents of 1903 . 
A

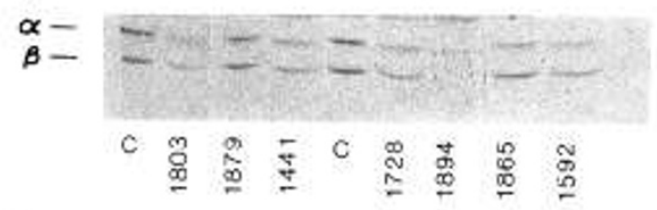

B

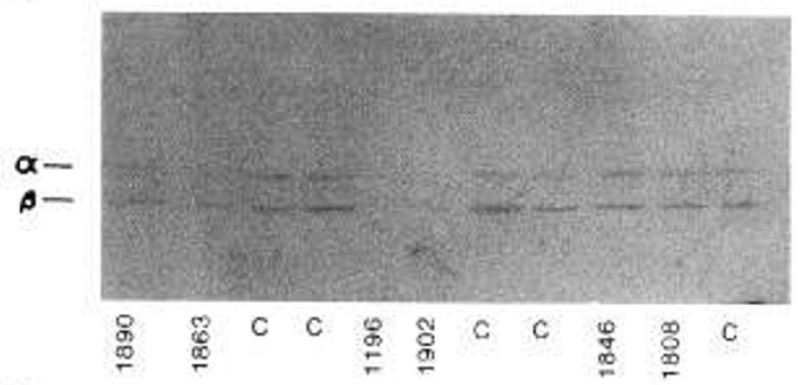

C

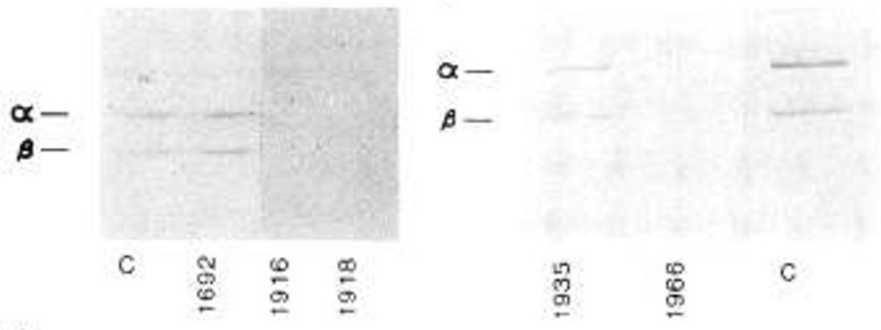

E

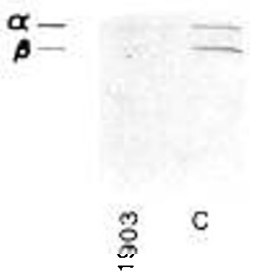

Fig. 2. Immunoblots of fibroblast extracts for $\alpha$ - and $\beta$-subunits of ETF. Control lines are in lanes designated $C$.

lines of particular interest, line 1894 appears to be deficient in the smaller $\beta$-subunit and line 1863, which has no detectable ETF activity, contains both subunits with apparently normal mol wt. Line 1916, derived from a patient with renal cysts and deficient in ETF activity contains no detectable ETF antigens. Further, in our previous study (3), patients without detectable ETF-QO activity all lacked detectable ETF-QO antigen. In this investigation, line 1879 has no detectable ETF-QO activity but contains ETF-QO antigen of normal mol wt and at a level comparable with control lines. The lower band in line 1935 (Fig. $3 C$ ) may reflect a truncated form of the protein.

\section{DISCUSSION}

Detailed biochemical investigation of a larger population of GA2 patients reveals that the clinical phenotype of GA2 is caused as often by a defect in ETF as by a defect in ETF-QO. In ETF deficiency, the residual electron transferase activity varies considerably and, in some cases without relation to clinical severity. For example, patient 1966, with a mild clinical course and intermittent organic aciduria, had lower ETF activity than several patients whose disease presented in infancy. This observation may reflect the relative instability in crude extracts of residual ETF activity in the different mutants. In contrast, the loss of ETF-QO activity was usually complete and antigen was usually undetectable in all patients with ETF-QO deficiency except patients 1808 and 1935, who had milder disease, and most of these patients had renal cystic dysplasia.
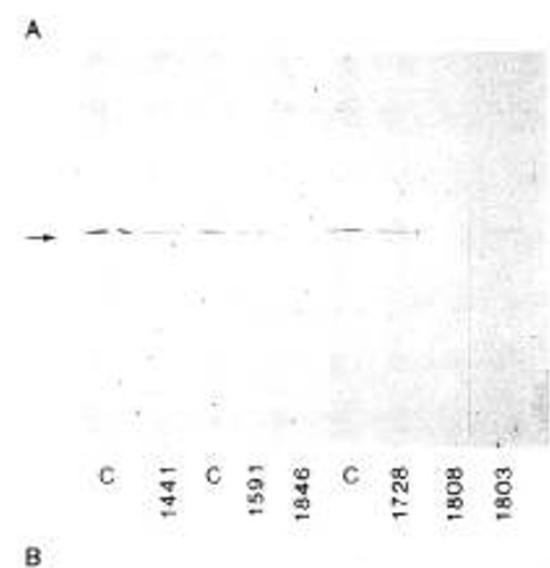

B

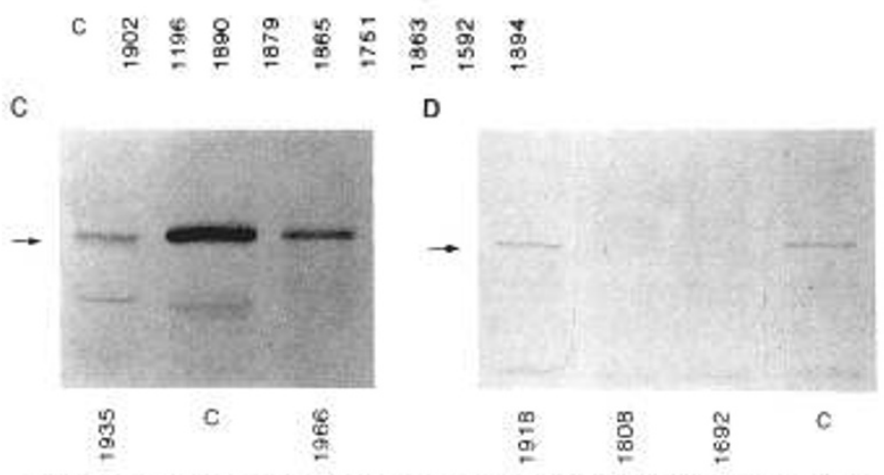

Fig. 3. Immunoblots of fibroblast extracts for ETF-QO antigen Control lines are in lanes designated $C$.

The results obtained with patient 1591 are not clear. The patient's fibroblasts had $17 \%$ of mean ETF-QO activity of controls when assayed by comproportionation of $\mathrm{ETF}_{\mathrm{ox}}$ and

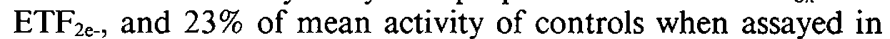
the NADH-ETF reductase reaction (12) (data not shown). ETF activity was $42 \%$ of the mean activity of controls. Unfortunately no internal control of mitochondrial enzyme activity, e.g. citrate synthase, was assayed that might help clarify this ambiguity.

The results on patient 1916 show that renal cystic dysplasia can also occur in ETF deficiency, suggesting that the malformations in these patients is due to either the decreased rate of electron transport or, if the genes for ETF and ETF-QO are closely linked, to a deletion that involves another gene as well. It is not clear why the malformations are more common in ETFQO deficiency, unless deficiency of ETF-QO is more complete than that of ETF. The fact that ETF-QO antigen is often absent in ETF-QO deficiency supports this contention, but anomalies are often absent in patients without detectable ETF antigen. The striking similarity of the anomalies in GA2 to those of Zellweger syndrome, almost certainly a disease of peroxisomes and not mitochondria, suggests a common pathogenic mechanism. ETF and ETF-QO were normal in the only Zellweger cell line that we have examined.

Patient 1903, with ETF deficiency, is the first GA2 patient reported with extrapyradmidal movement disorder, and neuronal degeneration and gliosis in the basal ganglia. These finding are more typical of glutaryl-CoA dehydrogenase deficiency (glutaric acidemia type I), and suggest that glutaric acid, the only compound that is accumulated in both diseases, is the cause of the striatal degeneration. Several suggestions have been made for how such toxicity could occur, including inhibition of neuronal 
glutamate decarboxylase or synaptosomal high affinity uptake of glutamate, and accumulation of quinolinic acid (28).

It is important to note that patients 1851 and 1966 , both with mild clinical disease, had barely detectable and intermittent organic aciduria, a feature that may make diagnosis difficult unless the abnormalities are present at the time of the initial examination.

The absence of detectable ETF and ETF-QO antigens does not necessarily mean that the polypeptide is not synthesized; rather, the absence of the antigen on immunoblots simply reflects the steady state level of the antigen compared with the level in a control fibroblast line. For example, our experiments did not detect ETF subunits in cell lines 1196 and 1902, whereas pulse labeling experiments show that both lines synthesize the smaller subunit (4). Immunoprecipitable precursor of the larger ETF subunit was not detected in line 1196, and was significantly decreased in line 1902, although the smaller subunit was pulse labeled in both cell lines. The difference between the two approaches lies in the fact that the immunoblotting technique does not differentiate between the capacity of the cell to synthesize the polypeptide and the stability of the peptide if it is synthesized. However, pulse labeling can indicate that the polypeptide is synthesized, but does not indicate whether the polypeptide is metabolically stable unless appropriate chase experiments are carried out. Also, in the case of cell line 1808, which contains about 3\% residual ETF-QO activity, we could not demonstrate ETF-QO antigen. This observation may reflect the sensitivity of the immunoblot method, instability of the antigen, or a mutation that affects a dominant epitope.

The assay for ETF we described was developed to overcome the possibility that assays using artificial electron acceptors might not be sensitive to mutations affecting a possibly distinct ETFQO binding site on ETF. This assay uses only physiologic ETF reductant and oxidant, i.e. MCAD and ETF-QO, and was adapted from a published assay for ETF-QO (5). The results show that the assay can be used to characterize GA2 cell lines, and that it is specific and does not require the isolation of fibroblast mitochondria for the sensitive detection of ETF activity.

Acknowledgments. The authors thank Christina Bemelen for her excellent technical assistance and Harriet McKelvey for growing the fibroblasts.

\section{REFERENCES}

1. Crane FL, Beinert H 1956 On the mechanism of dehydrogenation of fatty acyl derivatives of coenzyme A. The electron transferring flavoprotein. J Biol Chem 218:717-724

2. McKean MC, Beckmann JD, Frerman FE 1983 Subunit structure of electron transfer flavoprotein. J Biol Chem 258:1866-1870

3. Frerman FE, Goodman SI 1985 Deficiency of electron transfer flavoprotein or electron transfer flavoprotein ubiquinone oxidoreductase in glutaric acidemia type II fibroblasts. Proc Natl Acad Sci USA 82:4517-4520

4. Ikeda Y, Keese SM, Tanaka K 1986 Biosynthesis of electron transfer flavoprotein in a cell-free system and in cultured fibroblasts. J Clin Invest 78:9971002
5. Amendt BA, Rhead WJ 1986 The multiple acyl-CoA dehydrogenase disorders, glutaric aciduria type II and ethylmalonic-adipic aciduria. J Clin Invest 78:205-213

6. Ruzicka FJ, Beinert H 1977 A new component of the respiratory chain: a component of the fatty acid $\beta$-oxidation pathway. J Biol Chem 252:8440 8446

7. Beckmann JD, Frerman FE 1985 Electron transfer flavoprotein ubiquinone oxidoreductase from pig liver: purification and molecular, redox and catalytic properties. Biochemistry 24:3913-3921

8. Goodman SI, Frerman, FE 1984 Glutaric acidemia type II (multiple acyl-CoA dehydrogenation deficiency). J Inher Metab Dis 7(suppl 1):33-37

9. Bohm N, Uy J, Kiessling M, Lehnert W 1982 Multiple acyl-CoA dehydrogenase deficiency (Glutaric acidemia type II), congenital polycystic kidneys and symmetric warty dysplasia of the cerebral cortex in two brothers: morphology and pathogenesis. Eur J Pediatr 139:60-65

10. Mantagos S, Genel M, Tanaka K 1979 Ethylmalonic-acipic aciduria: in vivo and in vitro studies indicating deficiency of activities of multiple acyl-CoA dehydrogenases. J Clin Invest 64:1580-1589

11. Dusheiko G, Kew MC, Joffe BI, Lewis JR, Mantagos S, Tanaka K 1979 Recurrent hypoglycemia associated with glutaric acidemia type II in an adult. N Engl J Med 301:1405-1409

12. DiDonato S, Frerman FE, Rimoldi MS, Rinaldo P, Taroni F, Wiesmann UN 1986 Systemic carnitine deficiency due to lack of electron transfer flavoprotein-ubiquinone oxidoreductase. Neurology 36:957-963

13. Goodman SI, Stene DO, McCabe ERB, Norenberg MD, Shikes RH, Stumpf DA, Blackburn GK 1982 Glutaric acidemia type II: clinical, biochemical and morphologic considerations. J Ped 100:946-950

14. Przyrembel H, Wendel U, Becker K, Bremer JH, Bruinvis L, Ketting D, Wadman SK 1976 Glutaric aciduria type II: report on a previously undescribed metabolic disorder. Clin Chim Acta 66:227-239

15. Vergee $\mathrm{ZH}$, Sherwood WG 1985 Multiple acyl-CoA dehydrogenase deficiency: a neonatal case responsive to treatment. J Inher Metab Dis 8(suppl 2):137138

16. Niederwieser A, Steinmann B, Exner U, Neuheiser F, Redweik U, Wang M, Rampini S, Wendel U 1983 Multiple acyl-CoA dehydrogenase deficiency (MADD) in a boy with nonketotic hypoglycemia, hepatomegaly, muscle hypotonia and cardiomyopathy. Helv Pediatr Acta 38:9-26

17. Coude FX, Ogier H, Charpentier C, Thomassin G, Checoury A, AmedeeManesme O, Saudubray JM, Frezel J 1981 Neonatal glutaric aciduria type II: an X-linked recessive inherited disorder. Hum Genet 59:263-265

18. Mandel H, Alfrick D, Blitzer M, Shapira E 1988 The importance of recognizing secondary carnitine deficiency in organic acidemias: case report in glutaric acidemia type II. J Inherited Metab Dis 1 1:397-402

19. Moon A, Rhead WJ 1987 Complementation analysis of fatty acid oxidation disorders. J Clin Invest 79:59-64

20. McKean MC, Frerman FE, Mielke DM 1979 General acyl-CoA dehydrogenase from pig liver: kinetic and binding studies. J Biol Chem 254:2730-2735

21. Gorelick RJ, Shopfer LM, Ballou, DP, Massey V, Thorpe C 1985 Interflavin oxidation-reduction reaction between pig kidney general acyl-CoA dehydrogenase and electron transfer flavoprotein. Biochemistry 24:6830-6839

22. Husain M, Steenkamp DJ 1983 Electron transfer flavoprotein from pig liver. Biochem J 209:541-545

23. Ramsay RR, Steenkamp DJ, Husain M 1987 Reactions of electron transfer flavoprotein and electron transfer flavoprotein-ubiquinone oxidoreductase. Biochem J 241:883-892

24. Lowry O, Rosebrough NJ, Farr AL, Randall RJ 1951 Protein measurement with the Folin reagent. J Biol Chem 193:265-275

25. Miller GL 1959 Protein determination for large numbers of samples. Anal Chem 31:964

26. Laemmli UK 1971 Cleavage of structural proteins during the assembly of the head of bacteriophage T4. Nature 227:680-685

27. Burnette WN 1981 "Western Blotting": electrophoretic transfer of proteins from sodium dodecyl sulfate-polyacrylamide gels to unmodified nitrocellulose and radiographic detection with antibody and radiolabeled protein $\mathrm{A}$. Anal Biochem 112:195-203

28. Goodman SI, Frerman FE 1989 Organic acidemias due to defect in lysine oxidation: 2-ketoadipic acidemia and glutaric acidemia. In: Scriver CR, Baudet AL, Sly WS, Valle D (eds) Metabolic Basis of Inherited Disease, 6th ed, Vol 1. 6th Edition, McGraw-Hill, New York, pp 845-853 